\title{
A EFETIVAÇÃO DO DIREITO À APOSENTADORIA ESPECIAL DAS PESSOAS PORTADORAS DE DEFICIÊNCIAS
}

\author{
Regina Toledo Damião
}

Doutora em Direito, Mestre em Educação, Artes e História da Cultura, Especialista em Didática do Ensino Superior em Direito, Autora de diversas publicações, entre elas: Técnica Legislativa, coautora do Curso de Português Jurídico, Membro Fundador da Academia Paulista de Letras Jurídicas, Professora Aposentada como Titular de Direito Civil e Linguagem Jurídica pela Universidade Presbiteriana Mackenzie, Professora de EAD dos Cursos de Especialização em Gestão Ambiental e Direito Previdenciário das Universidades Municipal de São Caetano do Sul e Estácio de Sá, nesta última também Professora de Metodologia da Pesquisa II e Orientadora de TCCs em Direito Previdenciário. Curriculum lattes: http://lattes. cnpq.br/3312338859805181.

Sybelle Luzia Guimarães Drumond

Doutoranda em Direito Público e Evolução Social pela Universidade Estácio de Sá. Mestre em Direito Econômico e Desenvolvimento pela Universidade Cândido Mendes. Pós-Graduada em Direito Previdenciário pela Universidade Estácio de Sá. Pós-Graduada em Direito Tributário pela Universidade Gama Filho. MBA em Gestão Empresarial pela Fundação Getúlio Vargas. Graduação em Direito pela Universidade Estácio de Sá. Pós-Graduada em Métodos Estatísticos Computacionais pela Universidade Federal de Juiz de Fora. Graduada em Farmácia-Bioquímica pela Universidade Federal de Juiz de Fora. Curriculum lattes: http://lattes.cnpq. br/7064289686111928. Email: sybelle.drumond@gmail.com

\section{Resumo}

O presente artigo tem como objetivo abordar o interesse constitucional e infraconstitucional brasileiro pela proteção das Pessoas Portadoras de Deficiência (PPDs) sob a ótica de sua efetividade, em especial no caso da regulamentaçáo da respectiva aposentadoria especial.

Para tanto, faz-se breve incursão em documentos internacionais e nacionais sobre a questão e seu propósito inclusivo. Em linhas gerais, tem-se como referencial os direitos assegurados pela Convenção da ONU e pela Política Nacional Brasileira de Inclusão do Deficiente na realidade social, com ênfase na sua Aposentadoria Especial, regulada pela Lei Complementar n ${ }^{\circ} 142$ de 2013. Permeando a pesquisa, são feitas intervençóes críticas com a intenção de demonstrar o entrave burocrático que ainda persiste na efetivaçáo 
do direito à aposentadoria especial e a recorrente dificuldade brasileira de fazer de uma lei, um fato.

\section{Palavras-chave}

Efetividade; Aposentadoria Especial; Pessoa Portadora de Deficiência; Lei Complementar $n^{\circ} 142$ do 2013 .

\section{Abstract}

This paper aims to address the constitutional and infraconstitucional Brazilian purpose for the protection of Persons with Disabilities (PPDs) from the perspective of their effectiveness, especially in the case of regulations of the respective special retirement.

Therefore, it is brief foray into national and international documents on the issue and its comprehensive purpose. Generally speaking, it has as a reference the rights guaranteed by the UN Convention and the Brazilian National Policy on Disability Inclusion in social reality, with emphasis on their Special Retirement, regulated by Complementary Law No. 142 of 2013. Permeating the research are made critical interventions intended to demonstrate the bureaucratic obstacle that still persists in ensuring the right to special retirement and the recurrent Brazilian difficulty of transforming a law in a fact.

\section{Key words}

Effectiveness; Special Retirement; Persons with Disabilities; Complementary Law No. 142 of 2013.

\section{Introdução}

No Brasil, a proteção social teve início na assistência privada, com obras religiosas e açôes particulares. Com o advento da Constituição Republicana de 1891, foi instituída a aposentadoria por invalidez para o servidor público. Houve, também, a edição de várias leis e decretos que criaram caixas de aposentadoria e pensão. Por meio da Lei Eloy Chaves, Decreto Legislativo 4.682 de 24.01.1923, autorizou-se a criação das Caixas de Aposentadoria e Pensóes (CAPs), que possuem natureza privada. Este modelo foi estendido para outras empresas.

As Constituiçóes de 1937 e de 1946 aumentaram consideravelmente a cobertura da Previdência Social, mas careciam, ainda, de uniformização para as regulamentaçóes das Caixas e dos Institutos de Previdência Social o que só ocorreu com a Lei Orgânica da Previdência Social, Lei 3.807 de 26.08.1960. Inovaçóes no campo da Previdência Social sucederam-se ao longo dos anos, introduzindo, na Constituição Federal de 1988, novo 
modelo de proteção: a Seguridade Social. A edição de Medidas Provisórias e reformas por meio de Emendas Constitucionais foram, também, instrumentos de garantias previdenciárias, inserindo, nesse contexto, proteção às pessoas com deficiências, objetivando incluí -las no meio social, permitindo-lhes a superação de obstáculos e preconceitos enfrentados diariamente.

Diferenças há nos contextos sociais e jurídicos da comunidade internacional. Por isso, é de extrema importância o esforço da ONU e dos Estados que já ratificaram a Convenção sobre os Direitos das Pessoas com Deficiência, objetivando sua universalização.

Expostas essas observaçóes, o interesse da pesquisa é tecer breves consideraçóes sobre a proteção dos portadores em diplomas internacionais para, então, analisar a política inclusiva no Brasil e apreciar sua efetividade.

\section{Proteção à Pessoa Portadora de Deficiência}

\subsection{As Pessoas Portadotas de Deficiências (PPDs) no Ordenamento Internacional}

Após a Segunda Guerra Mundial, a questão das minorias deixou de ser analisada somente sob o aspecto político e passou a ser vista pelo prisma humanitário, mais amplo, sem a limitação territorial.

É importante ressaltar que a edificação dos direitos humanos das pessoas com deficiência ocorreu após as duas guerras mundiais pelo aumento do número de deficiências de locomoção, de audição e de visão, como um dos perversos efeitos daqueles conflitos, tornando-se necessária a proteção dos Estados.

No âmbito internacional, surgiu um conjunto de regras, com diversas aplicaçôes, em aparatos jurídicos próprios. Neste viés, cumpre separar os sistemas global, regional e local de proteção dos direitos humanos, especialmente direcionados à pessoa com deficiência.

As convençóes internacionais integram o sistema global de proteção e são produzidas no âmbito da ONU, com representaçáo de Estados da comunidade internacional, denominados de Estados-partes.

Além do sistema global, há, ainda, o sistema regional que busca a proteção de direitos no âmbito de uma região. Atualmente, há três planos regionais de proteção: o europeu, o interamericano e o africano. Ainda estão em formação mais dois sistemas: o árabe e o asiático.

No âmbito local, chamado de interno, a Constituição Federal de 1988, em seu preâmbulo, instituiu o Estado Democrático "destinado a assegurar o exercício dos direitos sociais e individuais: a liberdade, a segurança, o bem-estar, o desenvolvimento, a igualdade e a justiça, como valores supremos de uma sociedade fraterna, pluralista 
e sem preconceitos, fundada na harmonia social e comprometida na ordem interna e internacional.” (BRASIL, 1998)

A aplicação imediata das normas constitucionais confere força normativa aos preceitos referentes a direitos, liberdades e garantias fundamentais, prevendo um regime jurídico específico endereçado a tais direitos.

A proteção dos direitos humanos nos termos do sistema internacional tem, como base para a criação de políticas públicas, a Declaração Universal dos Direitos Humanos.

\subsubsection{Declaração Universal dos Direitos Humanos}

A Declaração Universal dos Direitos Humanos $^{1}$ foi aprovada pela Assembléia Geral das Naçóes Unidas em 10 de dezembro de 1948, pela Resolução n. 217, por 48 votos a zero, com abstenção da Bielorússia, Checoslováquia, Polônia, Arábia Saudita, Ucrânia, União Soviética, África do Sul e Iugoslávia.

Interessante é anotar que a ONU, ainda na fase de elaboração da Declaração Universal dos Direitos Humanos, iniciou um processo paralelo de proteção especializada contra certos tipos de violação e para determinados grupos de indivíduos, cujas características especiais exigiam atenção particular e normas específicas, a saber: minorias raciais, mulheres, crianças, migrantes e, vale destacar, pessoas com deficiência, não raro, submetidas a tratamentos degradantes.

A busca de meios para assegurar garantias especiais a esses indivíduos e grupos mais vulneráveis, fortaleceu o caráter universal dos direitos dispostos na Declaração Universal².

1 Embora não faça menção expressa à pessoa com deficiência, a Declaração Universal dos Direitos Humanos dispóe em seu artigo XXIII, 1, que "toda pessoa tem direito ao trabalho, à livre escolha de emprego, a condiçôes justas e favoráveis de trabalho e à proteção contra o desemprego". O seu artigo II dispóe que: 1.Toda pessoa tem capacidade para gozar os direitos e as liberdades estabelecidas nesta Declaração, sem distinção de qualquer espécie, seja de raça, cor, sexo, língua, religião, opiniấo política ou de outra natureza, origem nacional ou social, riqueza, nascimento, ou qualquer outra condição. 2. Não será tampouco feita qualquer distinção fundada na condição política, jurídica ou internacional do país ou território a que pertença uma pessoa, quer se trate de um território independente, sob tutela, sem governo próprio, quer sujeito a qualquer outra limitação de soberania.

2 No âmbito da ONU, juntamente com a Declaração Universal dos Direitos Humanos, existem hoje oito convençóes internacionais reputadas como essenciais, por sua ampla e constante aplicabilidade, que compóem o cerne do sistema jurídico-normativo internacional dos direitos fundamentais do ser humano. São elas: 1) o Pacto Internacional dos Direitos Econômicos, Sociais e Culturais; 2) o Pacto Internacional dos Direitos Civis e Políticos; 3) a Convenção Internacional sobre a Eliminação de todas as Formas de Discriminação Racial; 4) a Convenção sobre a Eliminação de todas as Formas de Discriminação contra a Mulher; 5) a Convenção contra a Tortura e outros Tratamentos ou Penas Cruéis, Desumanos ou Degradantes; 6) a Convenção sobre os Direitos da Criança; 7) a Convenção Internacional sobre a Proteção dos Direitos de todos os Trabalhadores Migrantes e Membros de suas Famílias e 8) a Convençấo Internacional sobre os Direitos das Pessoas com Deficiência. 


\subsubsection{Declaração dos Direitos do Deficiente Mental e Declaração dos Direitos das Pessoas Portadoras de Deficiência}

A Declaração dos Direitos do Deficiente $\mathrm{Mental}^{3}$ foi promulgada pela Assembléias Geral da ONU em 20 de dezembro de 1971. A Declaração prevê, ainda, os direitos à segurança econômica, a nível de vida condigno, ao exercício de atividade produtiva ou alguma outra ocupação útil ( $\operatorname{art.} 3^{\circ}$ ), bem como sua proteção de toda exploração e de todo abuso ou tratamento degradante (art. $6^{\circ}, 1^{\mathrm{a}}$ parte).

Esse diploma determina que a pessoa com deficiência intelectual deve residir com sua família, ou em lar que substitua o seu, e participar das diferentes formas de vida em sociedade. Havendo internação, ela deverá ocorrer em estabelecimento especializado e condizente com as condiçóes normais da vida.

A Declaração dos Direitos das Pessoas Portadoras de Deficiência, promulgada pela Assembléia Geral das Naçóes Unidas, em 9 de dezembro de 1975, possui maior abrangência, pois refere-se a todas as pessoas com deficiência, reiterando questóes já tratadas pela Declaração de Direitos do Deficiente Mental, em especial, direitos civis e políticos, destacando a necessidade de convívio familiar e de proteção contra exploração e tratamento de natureza discriminatória, abusiva ou degradante, conforme já se aventou anteriormente ${ }^{4}$.

A normatização protetiva das pessoas com deficiência ${ }^{5}$ conferiu-lhes tratamento igualitário, sem discriminação, enumerando, entre outras, as de raça, cor, sexo, língua, religião, opiniōes políticas que digam respeito à pessoa com deficiência ou a seu convívio familiar.

Os temas tratados nos treze artigos da Declaração dos Direitos das Pessoas Portadoras de Deficiência foram ampliados e complementados pela Convenção Internacional sobre os Direitos das Pessoas com Deficiência, de 6 de dezembro de 2006, adiante explicada.

\subsubsection{Convenção Internacional sobre os Direitos das Pessoas com Deficiência}

Objetivando a proteção global especializada das pessoas com deficiência, foi celebrada a Convenção Internacional sobre os Direitos das Pessoas com Deficiência, aprovada

3 A Declaração dos Direitos do Deficiente Mental é um diploma específico sobre os direitos das pessoas com deficiência intelectual. Assegura os direitos de gozar os mesmos direitos das demais pessoas, à atenção médica e aos tratamentos exigidos pelo seu caso, como também os direitos à educação, à capacitação profissional, à reabilitação e à orientação que lhes permitam desenvolver ao máximo suas aptidōes e possibilidades (arts. $1^{\circ}$ e $2^{\circ}$ da Declaração).

4 Disposição prevista nos arts. $4^{\circ}, 9^{\circ}$ e $10^{\circ}$ da Declaração das Pessoas Portadoras de Deficiência.

5 O termo "pessoas deficientes" refere-se a qualquer pessoa incapaz de assegurar por si mesma, total ou parcialmente, as necessidades de uma vida individual ou social normal, em decorrência de uma deficiência, congênita ou não, em suas capacidades físicas ou mentais (art. $1^{\circ}$ da Declaração das Pessoas Portadoras de Deficiência). 
pela Assembléia Geral das Nações Unidas, em 6 de dezembro de 2006, e subscrita pelo Brasil em 30 de março de 2007. A Convenção e seu Protocolo Facultativo foram ratificados pelo Congresso Nacional Brasileiro, em 9 de julho de 2008, pelo Decreto Legislativo no 186 , de 9 de julho.

A Convenção ${ }^{6}$ contou com a participação direta de Organizações Não Governamentais, ONGs, de pessoas com deficiência, vozes ativas na sua elaboração, inserindo-se em processo constante de inovação na construção dos direitos humanos.

Ademais, a Convenção Internacional sobre os Dirietos da Pessoa com Deficiência ${ }^{7}$ indica seu objetivo em seu primeiro artigo: "promover, proteger e assegurar o desfrute pleno e equitativo de todos os direitos humanos e liberdades fundamentais por parte de todas as pessoas com deficiência e promover o respeito pela sua inerente dignidade". Em sua segunda parte, adverte "ser a deficiência um conceito em evolução e resultado das barreiras atitudinais e ambientais que impedem sua plena e efetiva participaçáo na sociedade, em igualdade de oportunidades com as demais pessoas".

$\mathrm{O}$ artigo $3^{\circ}$ elenca seus princípios ${ }^{8}$, garante a independência, autonomia e a inclusão social das pessoas com deficiência. $\mathrm{O}$ artigo $4^{\circ}$ enumera as obrigaçóes gerais dos Estados -partes para a plena realização de todos os direitos humanos e liberdades fundamentais das pessoas com deficiência, dentre elas, medidas antidiscriminatórias, cooperação internacional e a elaboração e implementação de legislação e políticas para a execução dos preceitos da Convenção, exigindo dos Estados-partes medidas necessárias para obtenção de efetiva igualdade de condições para as pessoas com deficiência, acelerando esse processo como prioridade de política pública. Nessa seara, conclama o compromisso estatal

6 Esse diploma contém cinquenta artigos que asseguram à pessoa com deficiência muitos direitos humanos e liberdades fundamentais, dentre os quais destacamos: direitos econômicos, sociais e culturais (art. 4, 2), à igualdade e não discriminação (art. 5), de acessibilidade (art. 9), à vida (art. 10), à igualdade (art. 12), de acesso à justiça (art. 13), à liberdade e segurança (arts. 14 e 18), à vida e inclusăo na comunidade (art. 19), à liberdade de expressão e de opiniāo e acesso à informação (art. 21), à privacidade (art. 22), à educação (art. 24), à saúde (art. 25), habilitação e reabilitação (art. 26), ao trabalho e emprego (art. 27), à participação na vida política (art. 29), à cultura, recreaçâo, lazer e esporte (art. 30), entre outros.

7 A convenção traz o conceito de pessoas com deficiência como sendo: "Pessoas com deficiência são aquelas que têm impedimentos de natureza física, intelectual ou sensorial, os quais, em interação com diversas barreiras, podem obstruir sua participação plena e efetiva na sociedade com as demais pessoas."

8 Os princípios previstos no artigo $3^{\circ}$ correspondem a) o respeito pela dignidade inerente, independência da pessoa, inclusive a liberdade de fazer as próprias escolhas, e autonomia individual; b) a não discriminação; c) a plena e efetiva participaçáo e inclusão na sociedade; d) respeito pela diferença e pela aceitaçáo das pessoas com deficiência como parte da diversidade humana e da humanidade; e) a igualdade de oportunidades; f) a acessibilidade; g) a igualdade entre o homem e a mulher e; h) respeito pelas capacidades em desenvolvimento de crianças com deficiência e respeito pelo seu direito a preservar sua identidade. Esses princípios são normas direcionadas ao aplicador da Convenção, para que promova a dignidade da pessoa com deficiência, superando o modelo caritativo e eliminando os obstáculos culturais, tecnológicos e físicos para a sua efetiva inclusão social. 
de buscar a conscientização social e familiar para fomentar o respeito aos portadores de deficiência de qualquer natureza, além de combater esteriótipos preconceituosos.

O tema acessibilidade é tratado de forma abrangente pela Convenção, abordando as medidas a serem tomadas pelo Estado para assegurar o acesso ao meio físico, transporte, informação e comunicação, incluindo, ainda, a identificação e eliminação de obstáculos e barreiras e outras instalaçóes de acessibilidade, internas e externas, incluindo escolas, clínicas médicas e locais de trabalho.

Enfim, o reconhecimento de que pessoas com deficiência têm capacidade legal em igualdade de condiçóes aos demais, devendo o Estado tomar todas as medidas apropriadas e efetivas para assegurá-la, inclusive quanto ao igual direito de possuir e herdar bens, de controlar as próprias finanças e de ter igual acesso a empréstimos bancários, hipotecas e outras formas de crédito financeiro, devendo assegurar que as pessoas com deficiência não sejam arbitrariamente destituídas de seus bens.

O reconhecimento do direito das pessoas com deficiência ao trabalho e emprego, em igualdade de oportunidades aos demais, efetiva-se pela proibição de discriminaçáo da deficiência no recrutamento, admissão, permanência no emprego, ascensão profissional e condiçóes seguras e salubres de trabalho, além de direitos previdenciários compatíveis com suas limitaçóes, permitindo-lhes um padrão de vida digno.

No que se refere à acessibilidade aos meios culturais, recreação, lazer e esporte cabe ao Estado assegurar medidas apropriadas para que as pessoas com deficiência consigam desfrutá-los em igualdade de tratamento aos demais.

Por fim, o fato de o Brasil ter assinado a Convençáo, e principalmente, o Protocolo Facultativo, o caracteriza no âmbito internacional como um país que promove, protege e busca assegurar o desfrute pleno e equitativo dos direitos humanos e liberdades fundamentais a seus cidadãos, não olvidando os interesses e necessidades das pessoas com deficiência.

\subsection{Proteção a Pessoas Portadoras de Deficiência no Âmbito Nacional Brasileiro}

A análise do contexto da evolução histórica da Previdência Social no Brasil é necessária para acompanhar a evolução dos Direitos do Portador de Deficiência na Previdência Social.

Na década de 30, o sistema previdenciário foi estruturado em bases corporativistas, acompanhando o início do processo de industrialização do país. Em 1937, havia 183 CAPs instaladas. Além de inúmeros Institutos de Aposentadorias e Pensóes, restritos aos trabalhadores urbanos. 
Em 1960, a Lei Orgânica da Previdência Social, legislação aplicável aos Institutos, foi unificada mas sua gestão só o foi em 1966, com a criação do Instituto Nacional de Previdência Social (INPS) e, em 1974, com o surgimento do Ministério da Previdência e Assistência Social.

Até o ano de 1990, a Previdência Social no Brasil estava inserida no Sistema Nacional de Previdência e Assistência Social (SINPAS). Na área da saúde, o sistema abrangia o Instituto Nacional de Assistência Médica da Previdência Social (INAMPS) e a Central de Medicamentos (CEME). $\mathrm{Na}$ área da assistência social, compreendia a Fundação Nacional de Bem Estar do Menor (FUNA-BEM) e a Legião Brasileira de Assistência (LBA). Já a Previdência Social contava com o Instituto Nacional de Previdência Social (INPS), responsável pelo pagamento de benefícios monetários, o Instituto de Administração Financeira da Previdência e Assistência Social (IAPAS), responsável pela arrecadação, fiscalização e administração das contribuiçóes e a Dataprev, empresa de processamento de dados da Previdência Social.

O Instituto Nacional do Seguro Social (INSS) foi criado em 1990, produto da fusão dos extintos INPS e IAPAS, como autarquia vinculada ao Ministério da Previdência Social, com redes de atendimento distintas para os serviços de arrecadação e de fiscalização. Modernizada a sua estrutura, o INSS, braço operacional do Ministério da Previdência Social, passou a contar com uma diretoria colegiada, gerências executivas, além de postos de atendimentos.

A Medida Provisória, MP, n 222, em 2004, criou a Secretaria da Receita Previdenciária. O INSS deixou de cuidar da arrecadação e fiscalização das contribuições previdenciárias, exercendo a atribuição exclusiva do pagamento de benefícios e atendimento dos segurados. Em janeiro de 2005, a MP n 222 foi convertida em lei. Em 2007, as atribuiçóes da Secretaria da Receita Previdenciária passaram a integrar a recém criada Secretaria da Receita Federal do Brasil, vinculada ao Ministério da Fazenda.

Em 2009, foi criada a Previc, Superintendência Nacional de Previdência Complementar, autarquia especial vinculada ao Ministério da Previdência Social, com a função de supervisar e fiscalizar as entidades fechadas de previdência complementar, também conhecidas, no Brasil, como "fundos de pensão", de adesão voluntária e complementares ao Regime Geral de Previdência Social, com participação exclusiva de um grupo específico de empregados de uma empresa.

Enfim, o Direito Previdenciário, desde sua origem, tem por objetivo a cobertura dos "riscos sociais, tomada a expressão no seu sentido comum de acontecimento incertus an e incertus quando que acarrete uma situação de impossibilidade de sustento próprio e da família”. (JÚNIOR, 2005, p. 15)

A Constituição Federal de 1988, com seu caráter solidário, busca a aplicação da isonomia, propiciando ao portador de quaisquer das modalidades de deficiência, medidas 
protetivas que o colocam em igualdade de condiçôes aos demais segurados da Previdência Social, com o raciocínio de haver desigualdade para assegurar a igualdade entre pessoas desiguais, com condições laborais diferentes.

\subsubsection{Garantias Constitucionais às Pessoas Portadoras de Deficiências}

Conforme já explicado, a Seguridade Social é financiada por toda a sociedade, de forma direta e indireta, nos termos da lei, mediante recursos provenientes dos orçamentos da União, dos Estados, do Distrito Federal e dos Municípios, por meio de contribuições sociais listadas pelas Emendas Constitucionais no 20/98 e no 42/2003, prevendo benefício de prestação continuada ao deficiente.

A garantia constitucional do Benefício Previdenciário Continuado (BPC), regulamentada pela LOAS, (sigla cristalizada da Lei Orgânica da Assistência Social), norma infraconstitucional, é possível àqueles que não dispóem de meios de prover o próprio sustento nem tê-lo provido por sua família, devido à miserabilidade - definida em lei quando a renda mensal per capita não é superior a $1 \frac{1}{4}$ do salário mínimo - benefício destinado ao portador de deficiência ou à pessoa idosa de 65 anos.

Nesse diapasão, bom é ressaltar que a Constituição Federal de 1988, apesar de pouca efetividade quando suas normas apresentam natureza programática, demonstra evidente interesse pela proteção das pessoas portadoras de deficiência, podendo-se exemplificá-lo com alguns de seus dispositivos:

a) Art. 23, II - Dispóe sobre competências, quanto à assistência social e aos cuidados da saúde, faz referência expressa aos portadores de deficiência.

b) Art. 24, XIV - Exige a integração social das pessoas com deficiência.

c) Art. 27, II - Garante proteção às pessoas portadoras de deficiência, reiterando a obrigação protetiva dos entes federativos quanto à saúde e assistência social.

d) Art. 201, IV e V, no Capítulo da Ordem Social, dispóe sobre a obrigatoriedade de medidas protetivas, independentemenmte de contribuição ao custeio previdenciário, às pessoas portadoras de deficiência, com a garantia de um salário mínimo, quando não houver recursos para subsistência, ou ocorrer dependência de familiares para sobrevivência, reiteramdo o disposto no inciso II do mesmo artigo que exige assistência social aos menos favorecidos, incluindo expressamente as pessoas portadoras de deficiência.

e) Art. 227 - Prevê a assistência integral, incluindo as pessoas portadoras de deficiências físicas, sensoriais ou mentais, devendo-se promover medidas protetivas e tratamento especializado. 
f) Art. 244 - Estabelece a obrigatoriedade de Lei Complementar para regulamentação de acesso a logradouros, edifícios públicos e transportes coletivos.

Com esses exemplos, entre muitos outros, fica claro que os constituintes da Lei Magna de 1988 quiseram ressaltar a posição brasileira diante de políticas inclusivas recomendadas nos diplomas internacionais.

\subsubsection{Política Brasileira de Inclusão Social das Pessoas Portadoras de Deficiência}

A saúde é direito social fundamental e, como tal, é direito de aplicação imediata, conforme o artigo $5^{\circ}$, parágrafo $1^{\circ}$ da Constituição Federal, não se admitindo que o Estado Brasileiro se esquive de garanti-lo sob a alegação de que não existem condiçôes financeiras.

A deficiência é caracterizada por dificuldades fisiológicas no organismo que dificultam o funcionamento do cérebro, do sistema locomotor ou paralisia nos membros inferiores ou superiores. Ademais, pode ainda ser decorrência de fatores genéticos, fatores virais ou bacterianos e fatores traumáticos.

O artigo 198 da Constituição Federal estabelece que as açóes e serviços públicos de saúde constituem um Sistema Único de Saúde, SUS, financiado por recursos públicos, norteado pelas diretrizes da descentralização, possuindo uma direção para cada esfera de governo, tendo em vista atendimento integral de todos os casos e de todos os cidadãos.

O Estado, nos termos da Lei 7.853 de 1989 e do Decreto-Lei 3.298 de 1999, estabeleceu normas para assegurar o pleno exercício dos direitos individuais e sociais das pessoas portadoras de deficiência e sua efetiva integraçáo ao meio social, criando a Coordenadoria Nacional e a Política Nacional para a efetivação desse fim, assegurando-lhes, além dos direitos fundamentais, tratamento prioritário e adequado.

Nesse cenário, o exame admissional ou sequencial, realizado pela empresa em seus trabalhadores, tem considerável importância, tanto para o aspecto avaliativo da saúde do trabalhador, quanto para a descoberta de anomalias.

A forma mais comum de conclusão sobre uma deficiência é a apurada pela Previdência Social, no Regime Geral da Previdência Social (RGPS) ou do Regime Próprio da Previdência Social (RPPS). O exame médico feito pelas Forças Armadas, quando do serviço militar, tem localizado muitos incapacitados.

Desde as primeiras iniciativas de proteção ao portador de deficiência, a política inclusiva brasileira tem construindo acervo legislativo abundante sobre o assunto, em diversas áreas da vida em sociedade, podendo-se destacar algumas leis ou decretos sobre a matéria, como se verá: 
O Decreto-Lei ${ }^{\circ} 2.842$ de 7 de dezembro de 1940, ao legislar sobre crimes contra o trabalho, fixou, no parágrafo $2^{\circ}$ de seu artigo 209 , aumento de um sexto a um terço da pena para crimes cometidos contra vulneráveis, incluindo, entre eles, a pessoa portadora de deficiência física ou mental, náo distinguindo entre as primeiras, as de locomoção das sensoriais.

A Lei $n^{\circ} 4.616$, de 2 de abril de 1965, concedeu isenção de impostos de produtos importados e de consumo, além de taxa aduaneira para veículos adaptados de uso exclusivo de pessoas com defeitos físicos, impossibilitados de usarem modelos comuns.

A Lei 7.070, de 20 de dezembro de 1982, dispôs sobre pensão especial para deficientes físicos, mantida pelo INSS.

O Decreto-Lei no 2.236, de 23 de janeiro de 1985, dispensou a substituição obrigatória de documento de identidade estrangeiro, a cada nove anos, a contar de sua expedição, aos deficientes físicos.

A Lei 7.405, de 12 de novembro de 1985, tornou obrigatória a colocação de "Símbolo Internacional de Acesso" em todos os lugares e serviços utilizados por pessoas portadoras de deficiência

A Lei $n^{\circ} 7.853$, de 24 de outubro de 1989, legislou sobre a Coordenadoria Nacional para Integração de Pessoa Portadora de Deficiência para interesses coletivos e difusos daqueles a serem por ela protegidos, regulamentada pelo Decreto 3.298, de 20 de dezembro de 1989, ocasião em que estabeleceu a Política Nacional para Integração da Pessoa Portadora de Deficiência, determinando, em seu artigo $3^{\circ}$, proteção especial aos que tiveram perda de estruturaçóes de funçóes fisiológicas ou psicológicas, geradoras de incapacidade para o trabalho.

Importante documento legal para o tema, é a Lei 8.213 de 24 de julho de 1991, que estabeleceu o Plano de Benefícios da Previdência Social, regulamentando, entre outros, o auxílio-doença e a aposentadoria por invalidez.

Mais significativa, ainda, é a Lei no 8.742, denominada Lei Orgânica da Assistência Social, LOAS, regulamentadora do artigo 201, da Constituição Federal de 1988, em seu artigo $2^{\circ}, \mathrm{V}$, garantiudo a exigência já comentada anteriormente, vale recordar, salário mínimo como benefício mensal à pessoa portadora de deficiência quando não tiver meios de subsistência, dependendo exclusivamente de seus familiares.

Alguns diplomas legislativos têm aplicação particularizada, como ocorreu com a aprovação do Projeto de Lei 7.657/2014 que concedeu pensão mensal e vitalícia à atleta olímpica Laís da Silva Souza, com valor equivalente ao benefício máximo de R \$ 4.390,24 (quatro mil, trezentos e noventa reais e vinte e quatro centavos), intransferível.

Essa coleta aleatória de exemplos legislativos de proteção à pessoa portadora de deficiência demonstra a preocupação do legislador brasileiro com esses vulneráveis, esclareça-se, 
nunca sem antes ocorrerem reivindicaçóes exaustivas de ONGs e dos diversos setores da sociedade civil.

\section{Aposentadoria da Pessoa Portadora de Deficiência na Seguridade Social Brasileira}

O direito ao trabalho é um dos mais importantes dos direitos humanos e a inclusão social das pessoas com deficiência não se resume na sua inserção no mercado de trabalho, mas preocupa-se, também, com meio ambiente laboral, adequado e com a garantia de benefícios previdenciários diferenciados.

A política inclusiva brasileira tem-se preocupado cada vez mais em tornar produtivas as pessoas portadoras de deficiência que, no passado, eram vistas como fardo a ser suportado, particularmente os deficientes mentais, pela tradição greco-romana de cultuar a perfeição, considerando a inteligência como chave do sucesso profissional, na acepçáo preconceituosa de que só assim a pessoa torna-se produtiva.

Visando cumprir os princípios e normas da Convenção sobre os Direitos das Pessoas com Deficiência, da Organização das Naçóes Unidas (ONU), o Brasil lançou, em 2011, o Programa Viver sem Limites, que prevê a articulação de políticas governamentais de acesso à educação, atenção à saúde e respeito à acessibilidade.

Como se comentou alhures, o preâmbulo da Convenção estabelece, com base na Declaração Universal dos Direitos Humanos e nos Pactos Internacionais sobre Direitos Humanos, que toda pessoa faz jus a direitos e liberdades, sem distinção de qualquer espécie, bem como à garantia de que todas as pessoas com deficiências exerçam suas atividades de forma integral. A Constituição Federal de 1988, ao descrever sua concepção de deficiência, para a obtenção do benefício, exige incapacidade para o trabalho por um periodo mínimo de 2 anos ou mais.

Em época anterior à Lei 12.435 de 2011, os requisitos identificadores da deficiência eram definidos pela doutrina e pela jurisprudência, quais sejam: a) incapacidade considerada permanente ou temporária; b) incapacidade para o trabalho e para a vida independente, de forma cumulativa, ou alternativa.

No que se refere à concessão da aposentadoria especial, requer-se o atendimento ao binômio nocividade e permanência. A nocividade pode ser aferida de forma quantitativa e qualitativa. Para a permanência, há a exigência do trabalho por um período de 15, 20 ou 25 anos conforme o caso, com a exposição do agente nocivo, de forma náo ocasional nem intermitente.

$\mathrm{Na}$ aposentadoria especial, o coeficiente a ser aplicado sobre o salário-de-benefício para a definição da renda corresponde a 100\%. Sua concessáo depende de comprovação, 
pelo segurado, perante o INSS, do tempo de trabalho, além de exteriorizar características que o integram a listagem das modalidades de deficiências.

A aposentadoria diferenciada aos segurados portadores de deficiência foi regulamentada pela Lei Complementar no 142 de 2013 tornando o ordenamento aplicável, em especial a Emenda Constitucional no 47, de 2005 que previa sistema especial de inclusão previdenciária, com alíquotas e carências inferiores às dos demais segurados do Regime Geral da Previdência Social.

Aos contribuintes que optarem pelo sistema especial, não há direito de aposentaria por tempo de contribuição, mas somente por idade ou por invalidez. Também não se pode utilizar estas contribuições para contagem recíproca de tempo de contribuição, com o intuito de transferrir o tempo de contribuição do INSS para os Regimes Próprios o que, em regra, é permitido.

A carência compreende o número de contribuiçóes mensais necessárias para efetivação do direito a um benefício, sendo dispensada nos casos de doenças e afecçóes especificadas em lista elaborada pelos Ministérios da Saúde e da Previdência Social, de acordo com os critérios de estigma, deformação, mutilação, deficiência ou quaisquer fatores de especificidade e gravidade que mereçam tratamento particularizado, depois de o segurado ter-se filiado à Previdência Social. Veja-se que, interpretada a normatizaçáo em sentido literal, haveria obstáculos para as pessoas portadoras de deficiência ingressarem no mercado de trabalho, com direito às regras protetivas que o Sistema Previdenciário Brasileiro prevê aos portadores de deficiências, acionando-se amiúde o Judiciário.

\section{Efetivação da Garantia Constitucional na Aposentadoria Especial das Pes- soas Portadoras de Deficiência}

Após 25 anos de sua previsão constitucional, o Poder Executivo Federal sancionou a Lei que trata da aposentadoria especial de segurado filiado ao Regime Geral da Previdência Social, ou seja, a Lei Complementar no 142 de 2013 que reduz a idade e tempo de contribuição à Previdência Social para a aposentadoria de pessoa com deficiência, atendendo princípios, recomendaçóes e algumas disposiçóes que asseguram a proteção aos portadores de deficiência9 .

9 Os princípios que protegem os portadores de deficiência correspondem a: 1) Principio da Dignidade da Pessoa Humana; 2) Medidas para conter os preconceitos gerais da civilização nos termos do artigo 3, IV da Constituição Federal de 1988; 3) Igualdade entre os seres humanos: conforme o artigo $5^{\circ}$ da Constituição Federal de 1988; 4) Discriminação laboral: o artigo 7, XXXI da Constituição Federal de 1988; 5) Competência legislativa: 6) Habilitação e Integração. 7) Benefício do pagamento continuado; 8) Educação especializada; 9) Programa de prevenção e atendimento prioritário; 10) Acessibilidade urbanística. 
O trabalhador portador de deficiência foi classificado em três níveis diferentes. A Lei Complementar em tela separa a deficiência em grave, moderada e leve ${ }^{10}$. No enquadramento da deficiência grave, o deficiente precisa somar 25 anos (homens) e 20 anos (mulheres). Já a deficiência moderada precisa de 29 anos (homens) e 24 (mulheres). Para a deficiência leve, requer-se 33 anos (homens) e 28 (mulheres). Em todas, exige-se carência mínima de 15 anos de contribuição. No entanto, o texto não regulamenta, nem define os critérios objetivos para indicar o que é grave, moderado ou leve, necessitando de regulamentação para esclarecer esses aspectos.

Como se não bastassem os 25 anos de espera, para o surgimento dessa Lei Complementar, a regulamentação dos critérios de avaliação dos graus de deficiência só ocorreu na Portaria Interministerial de 27 de janeiro de 2014, superando, e muito, o prazo de sua implementação, exigindo, então, utilização da Tabela SUSEP ${ }^{11}$, órgão que define os critérios de seguros no Brasil rara pagar indenização em caso de invalidez.

O grau de deficiência é atestado por perícia própria do Instituto Nacional do Seguro Social, por meio de instrumentos desenvolvidos para esse fim. No entanto, a Lei não diz que instrumentos são esses, criando ainda mais incertezas quanto à concessão da nova aposentadoria e, por conseguinte, discussão no Judiciário que também tem sido acionado frequentemente para dirimir dúvidas sobre as perícias médicas do INSS, nem sempre confiáveis e muitas vezes desconstituídas por peritos judiciais, pois não é fácil ao deficiente conseguir se enquadrar nas diferentes modalidades de deficiência.

Além disso, a burocracia entrava a concessão do benefício. $\mathrm{Na}$ avaliação médica e funcional, exigida pela Lei, há um roteiro a ser seguido: data provável da deficiência e seu grau identificação da variação da deficiência e dos períodos de cada grau de deficiência.

Bom anotar, também, que a avaliação da funcionalidade da pessoa portadora de deficiência segue as normas da Classificação Internacional de Funcionalidade, Incapacidade e Saúde (CIF) da Organização Mundial da Saúde (OMS) e o Índice de Funcionalidade Brasileiro (IFBrA), aplicável para fins dessa aposentadoria especial. Não é ainda demais esclarecer que a tabela do CIF avalia o efeito da deficiência na limitação da atividade laboral para todas as modalidades, lembrando, física, sensorial e mental, levando-se em conta, também, sua participação, em todas relações sociais.

10 A Lei Complementar regulamenta o $\$ 1^{\circ}$ do art. 201 da Constituição Federal de 1988, que assim dispóe: "É vedada a adoção de requisitos e critérios diferenciados para a concessão de aposentadoria aos beneficiários do regime geral de previdência social, ressalvados os casos de atividades exercidas sob condiçốes especiais que prejudiquem a saúde ou a integridade física e quando se tratar de segurados portadores de deficiência, nos termos definidos em lei complementar".

11 SUSEP é o órgão responsável pelo controle e fiscalização dos mercados de seguro, previdência privada aberta, capitalização e resseguro. A SUSEP é uma autarquia que está vinculada ao Ministério da Fazenda, criada pelo Decreto-lei no 73, de 21 de novembro de 1966. 
Outro obstáculo para a efetividade do benefício foi que o agendamento de perícias só ter início em 03 de fevereiro de 2014, a despeito da previsão de entrar a Lei em vigor a partir de 04 de dezembro de 2013. Maior fragmentação temporal ocorreu nesse demorado processo de implantação, pois as pericías só tiveram início em março de 2014, obstaculizando a vigência da Lei Complementar em análise.

Diante do que dispóe a norma jurídica, é missão dos Magistrados e Tribunais, quando invocados, aplicarem a lei em cada caso, usando de criatividade com raciocínio lógico, aguçada sensibilidade e senso determinado de fazer Justiça.

Ao Ministério Público cabe a missão de postular no Judiciário, como guardião de direitos coletivos, o cumprimento efetivo de direitos quase sempre conferidos em ambiência de generalizaçóes, palavras semanticamente muito abertas e pouco claras e, não raro, sem regulamentação.

Todavia, ambos órgãos do Judiciário ficam entravados quando não há regulamentaçóes efetivas de leis, principalmente quanto às regras a serem aplicadas no período lacunoso que sobrevém quando se encerra a vacacio legis sem que haja as exigências de sua implantação, sendo desastroso seu resultado: entra em vigor uma lei, mas não sua efetivação.

Nesse impasse, o remédio constitucional do Mandado de Injunção é recurso judicial usado para questionar omissóes do Poder Legislativo na regulamentação de direitos constitucionais, em sua maioria, de natureza programática. Em comentada decisão monocrática ${ }^{12}$ do Supremo Tribunal Federal, o Ministro Celso de Mello entendeu que o direito à aposentadoria especial está descrito no parágrafo $4^{\circ}$, Inciso I, do artigo $40 \mathrm{da}$ Constituição e já deveria ter sido regulamentado pelo Congresso. Como não o foi, é de ser aplicada, por analogia, a regra prevista no artigo 57 da Lei 8.213/1991, a Lei de Custeio da Previdência.

Lamentáveis as dificuldades encontradas aos demandantes diante da omissão legislativa para a execução do seu direito, pois a Autoridade Administrativa a qual o comando injuncional se dirigia e era supletivo da lei faltante, impôs duas condiçóes para atender a decisão injuncional do Supremo Tribunal Federal:

12 A matéria da aposentadoria especial do servidor público foi julgada pela primeira vez através do mandado de injunção 721/DF pelo relator Ministro Marco Aurélio em 30/08/2007 pelo Tribunal Pleno. O STF reconheceu que a inexistência de lei específicia para o exercício do direito constitucional à aposentadoria com tempo de serviço reduzido, determinou a aplicaçáo temporária do art. 57 da Lei 8.213 de 1991. Da mesma forma em que autorizou o julgamento monocrático de todos os demais processos que tivessem o mesmo objeto, evitando assim que cada caso fosse levado ao plenário. Como resultado teve-se a consolidação do entendimento jurisprudencial da aplicação analógica do art 57 da Lei 8.213 de 1991 para a regulamentação da aposentadoria especial dos servidores públicos. A aplicação do art. 57 da Lei 8.213 de 1991 é limitada, não se dá de forma integrativa. Deve-se considerar a súmula vinculante 33 do Supremo Tribunal Federal, a qual dispóe: Aplicam-se ao servidor público, no que couber, as regras do regime geral da previdência social sobre aposentadoria especial de que trata o artigo 40 , $\$ 4^{\circ}$, inciso III da Constituição Federal, até a edição de lei complementar específica. 
(i) lançamento do abono de permanência em folha, somente após o trânsito em julgado da decisão em sede de jurisdição constitucional;

(ii) aplicação dos valores de forma não retroativa.

Assim, o servidor com deficiência passou a legitimar-se à aposentadoria especial aos 25 anos de atividade e contribuição por força do acórdão exarado pelo Supremo Tribunal, gerando-se no sistema jurídico nacional a regra reguladora que faltava para o advento da efetividade do direito consagrado no artigo 40, parágrafo $4^{\circ}$, Inciso I, da Constituição Federal, direito estendido a todos, porque a carga normativa de um Mandado de Injunção tem projeção erga omnes. Vale recordar, nesse passo, que a decisão injuncional supre a omissão legislativa ainda que a lei, quando elaborada, dispuser de foma diferente da coisa julgada injuncional, não ocorrendo retroatividade para alcançar direitos já adquiridos para modificá-los.

Conforme comentários acima, a presidente Dilma Rousseff sancionou a Lei Complementar no 142 , em 08 de maio de 2013, sobre a aposentadoria das pessoas portadoras de deficiência, com vacatio legis de 6 meses de sua publicação oficial, regulamentando, assim, o artigo 201 da Constituição Federal. Entre as regras, a redução do tempo de contribuição e da idade para concessão da aposentadoria de acordo com o grau de deficiência do segurado.

Para a verificação da gravidade, a avaliação deve ser médica e funcional e o grau de deficiência atestado por perícia própria do Instituto Nacional do Seguro Social. Por esse sistema, a idade mínima para aposentadoria dessas pessoas é de 60 anos (homens) e 55 anos (mulheres). Para as deficiências graves, prevê-se contribuiçóes de 25 anos (homens) e 20 anos (mulheres). Já as deficiências físicas moderadas exigem 29 anos (homens) e 24 anos (mulheres), enquanto as leves, 33 anos (homens) e 28 anos (mulheres).

Para ter reconhecido o direito à aposentadoria nos moldes da Lei Complemenmmtar em análise, a deficiência deve acarretar impedimentos de longo prazo, seja de natureza física, sensorial ou mental, impeditivos da participação dessa pessoa na sociedade em igualdade de condiçóes aos que atendem as expectivas de padrão dito normal. A existência de deficiência anterior à data da vigência da lei deve ser certificada, inclusive quanto ao seu grau, sendo obrigatória a fixação da possível data do início da deficiência.

A deficiência sensorial ocorre quando um ou mais dos cinco sentidos (visão, audição, tato, olfato e paladar) não funcionam total ou parcialmente, como a perda parcial da visão ou da audição. Por deficiência física, entende-se a alteração total ou parcial de um ou mais segmentos do corpo humano que compromete a função física. Alguns exemplos são a paralisia cerebral, amputação ou ausência de membro, tetraplegia, paraplegia, dentre outros. Deficiência mental ou intelectual é o retardo, um problema no cérebro humano que leva seus portadores a um baixo rendimento cognitivo, ou seja, redução da capacidade 
intelectual quando comparada ao padrão considerado normal para idade, como ocorre com portadores de síndrome de Down, autismo, entre outras anomalias da saúde mental. Quanto mais grave a incapacidade impeditiva do trabalho, por sua restrita funcionalidade, menor o tempo de contribuiçáo para a aposentadoria especial por invalidez.

$\mathrm{Na}$ aposentadoria por invalidez, é necessária perícia médica no INSS a cada dois anos, com o objetivo de verificar se o motivo que impossibilitou o segurado de seguir trabalhando, persiste. No caso da aposentadoria especial para deficientes, exige-se tempo de contribuição reduzido e o benefício, uma vez concedido, correspondente a $100 \%$ do salário-de-contribuição. Importante se faz salientar que muitas vezes os deficientes não se enquadram no afastamento por invalidez, tendo de cumprir o tempo normal de contribuição. Há possibilidade de requerer acréscimo de $25 \%$ para garantir o salário de um cuidador. $\mathrm{O}$ valor total, porém, é limitado ao teto, cessando com a morte do beneficiário e a comprovação da real necessidade está sujeita à análise da perícia do INSS, sem a qual não terá natureza de assistência social.

\section{Conclusões}

A inclusão social da Pessoa Portadora de Deficiência assegura a concretude do princípio da Dignidade da Pessoa Humana e demais valores de um Estado Democrático de Direito, conforme preceitua a Constituição Federal de 1988.

O reconhecimento legislativo dos grupos, reiteradamente excluídos, como os negros, os indígenas e as pessoas portadoras de deficiências traz a aplicação do conceito de equidade que, aplicado efetivamente, elimina a discriminação e introduz uma relação mais justa entre pessoas de uma sociedade, bem como dos cidadãos com os poderes estatais, alinhando-se aos anseios da comunidade internacional.

O preenchimento dos requisitos para a concessão da aposentadoria especial, previsto no parágrafo $4^{\circ}$ do artigo 40 da Constituição Federal de 1988 refere-se apenas à contagem especial de tempo do serviço público para fins de concessão da aposentadoria no Regime Próprio da Previdência Social. A impetração de Mandado de Injunção junto ao Supremo Tribunal Federal tornou-se remédio jurídico recomendado para que se cumpram as normas constitucionais sobre direitos individuais e coletivos que não tenham sido adequadamente regulamentados pelo legislador.

Não é demais anotar que a legislação brasileira em quase nada se dirige ao deficiente mental pelo severo preconceito, primeiro no seio familiar, depois na escola, enfim, nas relaçóes sociais em geral. Nesse contexto, surgiu, principalmente nas liçóes acadêmicas dos cursos de Pedagogia, a expressão portador de necessidades especiais, pela rejeição do termo deficiência, apesar de ter sido a preocupação primeira das convençóes e declaraçóes internacionais. 
A Lei Complementar no 142 de 2013, a despeito de constituir-se importante conquista aos portadores de deficiência, possui diversas disposiçóes abstratas, por vezes obscuras, de modo a gerar grandes debates jurídicos em sua interpretação.

Apesar de decisão do Supremo Tribunal Federal favorável ao deficiente, no momento da execução do seu direito, a Autoridade Administrativa cria-lhe obstáculos, impondo condiçóes leoninas no cumprimento injuncional.

Além disso, na dúvida quanto à melhor abordagem da norma de colmatação eleita pelo Supremo Tribunal Federal para regular a matéria (artigo 57 da Lei 8.213/91), tormou-se recorrente invocar o princípio in dúbio pro fiscum.

O servidor público com deficiência passou a legitimar-se à aposentadoria especial aos 25 anos de atividade e de contribuição. O acórdão do STF, transitado em julgado nos autos do Mandado de Injunção $721 / \mathrm{DF}$, mediante o preenchimento das regras específicas, gerou no sistema jurídico nacional a regra reguladora que faltava para o advento da efetividade do direito consagrado no artigo 40, parágrafo $4^{\circ}$, Inciso I, da Constituição Federal, extensivo a todos, pois a carga normativa de um Mandado de Injunção tem projeção erga omnes naquilo que comportar aos titulares do mesmo direito em igualdade de condiçóes alcançando, entâo, o trabalhador do setor privado e as demais pessoas, mesmo as não filiadas no sistema previdenciário quando houver a finalidade de garantir a sobrevivência da vida humana.

Enfim, a Lei Complementar no 142 de 2013 constituiu-se em significativa conquista aos segurados do RGPS portadores de deficiência, mas náo afastou o sentimento de insegurança jurídica porque, desde sua origem, acenou possibilidade de modificaçôes na sua regulamentação pelo Poder Executivo, alargando, inclusive, a vacacio legis para seis meses de sua publicação.

Apesar de ser marco importante de proteção às pessoas portadoras de deficiências (PPDs), essa Lei acumula omissóes, generalizaçóes e dispositivos abstratos que, dependendo da forma a ser regulamentada, deve ensejar muitos embates judiciais.

Nesse passo, oportuno se faz assinalar que as Medidas Provisórias no 664 e 665, editadas nos estertores de 2014, exatamente em 30 de dezembro, alteraram muitos benefícios previdenciários, entre eles, auxílio-doença e aposentadoria por invalidez, como um dos instrumentos de política de ajustes fiscais, limitando alguns benefícios. Advirta-se que não estão elas ainda convertidas em Lei, em penosa tramitação nas Casas do Legislativo, com andamento, também, de Ação Direta de Inconstitucionalidade da MP no 664, perante o STF

Dessa forma, para que se faça realizar a tão decantada justiça social, a pessoa portadora de deficiência tem buscado seus direitos, não raro, nas vias judiciais, até mesmo por estarem faltantes normas reguladoras de aposentadoria especial nas diversas modalidades 
de deficiência, não tendo o INSS as enquadrado em critérios específicos e seguros de fixação de seus graus.

Tem-se dito, aqui e acolá, que o Brasil governa com imagem legislativa: a cada reivindicação que excita a mídia e a cada manifestaçáo que leva o povo às ruas, com espírito de cidadania, surgem Medidas Provisórias e Projetos de Lei, sem a devida regulamentação e aplicação efetivas.

Fica a ilusão de proteção social real. Resta a esperança de sua efetividade. Espera-se por novos fatos para novas leis.

Todavia, o povo brasileiro festeja estar em um Estado Democrático de Direito, depositando seus anseios na pátria livre e solidária.

\section{Referências}

ALEXY, Robert. Epilogo a la teoria de os derechos fundamentales. 66 Revista Espanhola do Derecho constitucional, 2002.

ARAÚJO, Luiz Alberto David. A proteçáo constitucional das pessoas portadoras de deficiência. $2^{\circ}$ ed. Brasilía: CORDE, 1996.

ASENSI, Felipe Dutra. Direito a saúde: práticas socias reinvidicatórias e sua efetivação. Curitiba: Ed Juruá - FGV Direito Rio, 2013.

BALERA, Wagner. A contribuiçáo social sobre o lucro. Revista de Direito Tributário. São Paulo: Malheiros. 1996.

Contribuiçóes sociais. Caderno de Pesquisa Tributária. São Paulo: Centro de Extensão Universitária e Editora Resenha Tributária. n. 17. abr. 1992.

BRAGANÇA, Kerlly Huback. Manual de direito previdenciário. $8^{\circ}$ ed. revisada e ampliada. Rio de Janeiro: Editora Forense, 2012.

BRASIL, Constituiçáo da República de 1988. Disponível em: http://www.planalto.gov. br/ccivil_03/constituicao/constituicaocompilado.htm. Acesso em: 20 de Fevereiro de 2015 .

. Decreto-Legislativo $\mathbf{n}^{\circ} \mathbf{1 8 6}$ de 2008. Disponível em: http://www.planalto.gov. br/ccivil_03/constituicao/congresso/DLG/DLG-186-2008.htm. Acesso em: 20 de Março de 2015.

Decreto-Lei $\mathbf{n}^{\circ}$ 2.236 de 1985. Disponível em: http://www.planalto.gov.br/ ccivil_03/decreto-lei/del2236.htm. Acesso em: 20 de Março de 2015.

. Decreto-Lei no 2.842 de 1940. Disponível em: http://www2.camara.leg.br/ legin/fed/declei/1940-1949/decreto-lei-2842-5-dezembro-1940-412889-publicacaooriginal-1-pe.html. Acesso em: 21 de Março de 2015. 
Decreto $n^{\circ} 3.298$ de 1999. Disponível em: http://www.planalto.gov.br/ccivil_03/decreto/d3298.htm. Acesso em: 20 de Março de 2015.

. Decreto $n^{\circ} 4.682$ de 1923. Disponível em: http://www.planalto.gov.br/ccivil_03/decreto/Historicos/DPL/DPL4682.htm. Acesso em: 22 de Março de 2015.

. Decreto $n^{\circ}$ 6.949 de 2009. Disponível em: http://www.planalto.gov.br/ccivil_03/_ato2007-2010/2009/decreto/d6949.htm. Acesso em: 22 de Março de 2015.

. Lei no 3.807 de 1960. Disponível em: http://www.planalto.gov.br/ccivil_03/ leis/1950-1969/L3807.htm Acesso em: 20 de Março de 2015.

. Lei $\mathbf{n}^{\circ}$ 4.616 de 1965. Disponível em: http://www2.camara.leg.br/legin/fed/ lei/1960-1969/lei-4616-15-abril-1965-377864-publicacaooriginal-1-pl.html. Acesso em: 22 de Março de 2015.

. Lei $\mathbf{n}^{\circ}$ 7.070 de 1982. Disponível em: http://www.planalto.gov.br/ccivil_03/ leis/1980-1988/L7070.htm Acesso em: 20 de Março de 2015.

. Lei $\mathbf{n}^{\circ}$ 7.405 de 1985. Disponível em: http://www.planalto.gov.br/ccivil_03/ leis/1980-1988/L7405.htm. Acesso em: 20 de Março de 2015.

. Lei $\mathbf{n}^{\circ}$ 7.657 de 2014. Disponível em: http://www.planalto.gov.br/ccivil_03/_ Ato2011-2014/2011/Decreto/D7657.htm Acesso em: 20 de Março de 2015.

. Lei $\mathbf{n}^{\circ}$ 7.853 de 1989. Disponível em: http://www.planalto.gov.br/ccivil_03/ leis/17853.htm. Acesso em: 20 de Março de 2015.

. Lei ${ }^{\circ}$ 8.213 de 1991. Disponível em: http://www.planalto.gov.br/ccivil_03/ leis/18213cons.htm. Acesso em: 18 de Fevereiro de 2015.

. Lei $\mathbf{n}^{\circ} \mathbf{8 . 7 4 2}$ de 1993. Disponível em: http://www.planalto.gov.br/ccivil_03/ leis/18742.htm. Acesso em: 22 de Fevereiro de 2015.

. Lei $\mathbf{n}^{\circ}$ 12.435 de 2011. Disponível em: http://www.planalto.gov.br/ccivil_03/_ Ato2011-2014/2011/Lei/L12435.htm. Acesso em: 22 de Fevereiro de 2015.

. Lei Complementar $n^{\circ} 142$ de 2013. Disponível em: http://www.planalto.gov. br/ccivil_03/leis/lcp/Lcp142.htm. Acesso em: 20 de Feveriro de 2015.

CARVALHO RAMOS, Andre de. Direitos humanos em juízo. Comentários aos casos contenciosos e consultivos da Corte Interamericana de Direitos Humanos. São Paulo: Max Limonad, 2001.

COMPARATO, Fabio Konder. A afirmaçáo histórica dos direitos humanos. São Paulo: Ed. Saraiva, 2000.

DERZI, Mizabel Abreu Machado. Modificaçóes da jurisprudência no direito tributário. São Paulo: Ed Noeses, 2009. 
FERNÁNDEZ RODRÍGUEZ, T.R: De la arbitrariedad del legislador. Civitas, Madrid, 1998.

FONSECA, Ricardo Tadeu Marques da. A ONU e o seu conceito revolucionário de pessoa com deficiência. São Paulo: Ltr. 72-03/263, Vol. 72, nº. 03 Março de 2008.

GOMES, Joaquim Barbosa. Ação afirmativa \& princípios constitucionais da igualdade. Rio de Janeiro: Ed Renovar, 2001.

GOUVEIA, Carlos Alberto Vieira. Benefícios por incapacidade \& perícia médica. Manual Prático, 2a ed. Curitiba: Ed Juruá, 2014.

JÚNIOR, Miguel Horvath. Direito previdenciário. 5a ed. São Paulo: Ed. Quartier Latin, 2005.

PIOVESAN, Flávia. Direitos humanos e o direito constitucional internacional. $14^{\mathrm{a}}$ ed. rev., ampl. e atual. São Paulo: Editora Saraiva, 2013.

SARLET, Ingo Wolfgang. A eficácia dos direitos fundamentais. 10ª ed. Porto Alegre: Livraria do Advogado, 2009.

SOARES, João Marcelino; FOLMANN, Melissa. Coleção prática, processo e jurisprudencia previdenciaria, ediçáo atualizada de acordo com as Leis 12.435/11 e 12.470/11. Curitiba: Ed. Juruá: 2012.

TAVARES, Marcelo Leonardo Tavares, Direito previdenciário. $8^{\mathrm{a}}$ ed. Rio de Janeiro: Lumen Juris, 2006.

VIEIRA, Oscar Vilhena. A gramática dos direitos humanos, in 4. Boletim Cientifico da Escola Superior do Ministerio Publico da União, 2002.

Documentos:

Declaração de Direitos, 1689 (Bill of Rights).

Declaração dos Direitos do Homem e do Cidadão, 26 de agosto de 1789.

Declaração Universal dos Direitos Humanos, 10 de dezembro de 1948.

Declaração dos Direitos do Deficiente Mental, 22 de dezembro de 1971.

Declaração dos Direitos da Pessoa Portadora de Deficiência, 9 de dezembro de 1975. 